\title{
Diagnóstico e análise dos conflitos da arborização urbana: estudo de caso do bairro do Grajaú (Rio de Janeiro)
}

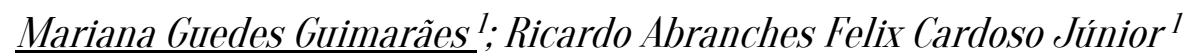

凶marigguima@gmail.com

1. Universidade Federal Fluminense, Rio de Janeiro, Brasil.

Histórico do Artigo:

Recebido em: 25 de setembro de 2018 Aceito em: 04 de dezembro de 2018 Publicado em: 30 de abril de 2019

Resumo: A arborização é um importante componente da paisagem urbana, proporcionando inúmeros benéficos relacionados ao bem estar da população. Neste trabalho foi realizado um diagnóstico da arborização urbana do bairro do Grajaú, localizado na cidade do Rio de janeiro, com ênfase no diagnóstico dos conflitos urbanos presentes, sendo o levantamento realizado entre agosto e novembro de 2016. Foram inventariados um total de 2.733 indivíduos arbóreos e arbustivos, correspondentes a 56 espécies, distribuídos em 22 ruas e avenidas do bairro. A espécie de maior abundância é a Amendoeira (Terminalia Catappa L), responsável por uma frequência de 15\% em relação ao total de árvores, seguido do Oiti (Licania Tomentosa (Benth.) Fritsch) com 11\% de indivíduos. Quanto à problemas no sistema radicular, apenas 13,4\% das árvores apontam algum tipo de dano. Em relação as copas das árvores, constata-se 87 indivíduos com a copa desequilibrada e isso representa um total de 3,2\% do total das árvores. 0s conflitos com a fachada, o telhado, a via e a rede elétrica são os que causam maiores problemas com os elementos urbanos. A fachada sendo mais expressiva, onde foram detectados 789 indivíduos conflitantes. A partir das informações coletadas em campo foi possível planejar o manejo arbóreo de forma confiável, objetivando priorizar as árvores e espécies que causam as maiores interferências com elementos urbanos.

Palavras-chave: Silvicultura urbana, conflitos urbanos, manejo florestal, censo arbóreo.

\section{Diagnosis and analysis of the urban silviculture conflicts: case study of the Grajaú district (Rio de Janeiro)}

\begin{abstract}
Silviculture is an important component of the urban landscape, providing countless benefits related to the well-being of the population. This work was carried out to diagnose the urban silviculture of the Grajaú neighborhood, located in the city of Rio de Janeiro, with emphasis on the present urban conflicts, through a survey made between and November of 2016. For the registration of the data, using a geoprocessing tool. A total of 2,733 arboreal and shrub individuals were reported, corresponding to 56 species, were dispersed in 22 streets and avenues of the neighborhood. The species of greater abundancy is the Amendoeira (Terminalia Catappa L), which represents $15 \%$ of the total of trees, followed by 0iti (Licania Tomentosa (Benth.) Fritsch) with 11\% of total individuals. In regard to the radicular system, only $13.4 \%$ of the trees indicate some damage. In terms to the treetops, there are 87 individuals with unbalanced canopy and this represents a total of $3.2 \%$ of the total trees. Conflicts with facade, roof, road and electric grid are the most prevailing problems that affect the urban elements. A facade is more significant where conflicting 789 individuals were detected. From the collected information, it is possible to plan the shrubs treatment reliably, focusing on prioritize the trees and species that cause the greatest interference with urban elements.
\end{abstract}

Keywords: Urban forestry, tree inventory, urban conflicts, tree census. 


\title{
Diagnóstico y análisis de los conflictos de la arborización urbana: estudio de caso del bairro del Grajaú (Río de Janeiro)
}

\begin{abstract}
Resumen: La arborización es un componente importante del paisaje urbano, proporcionando innumerables beneficiosos relacionados con el bienestar de la población. En este trabajo se realizó un diagnóstico de la arborización urbana del barrio del Grajaú, ubicado en la ciudad de Río de Janeiro, con énfasis en el diagnóstico de los conflictos urbanos presentes, siendo el levantamiento realizado entre agosto y noviembre de 2016. Fueron inventariados un total de 2.733 individuos arbóreos y arbustivos, correspondientes a 56 especies, distribuidos en 22 calles y avenidas del barrio. La especie de mayor abundancia es el almendro (Terminalia Catappa L), responsable de una frecuencia del 15\% en relación al total de árboles, seguido de 0iti (Licania Tomentosa (Benth.) Fritsch) con el 11\% de los individuos. En cuanto a los problemas en el sistema radicular, sólo el 13,4\% de los árboles señalan algún tipo de daño. En relación a las copas de los árboles, se constata 87 individuos con la copa desequilibrada y eso representa un total del 3,2\% del total de los árboles. Los conflictos con la fachada, el tejado, la vía y la red eléctrica son los que causan mayores problemas con los elementos urbanos. La fachada siendo más expresiva, donde fueron detectados 789 individuos conflictivos. A partir de las informaciones recolectadas en campo fue posible planificar el manejo arbóreo de forma confiable, objetivando priorizar los árboles y especies que causan las mayores interferencias con elementos urbanos.
\end{abstract}

Palabras clave: Silvicultura urbana, conflictos urbanos, manejo forestal, censo abóreo.

\section{INTRODUÇÃo}

A arborização urbana no Brasil é considerada um tema recente do qual as administrações públicas e comunidades devem se envolver, cumprindo papéis distintos. Atualmente, em cidades onde ocorre o planejamento da arborização, a preocupação é tornar o ambiente urbano diversificado quanto às espécies empregadas, mais homogêneo e envolvente com a paisagem circundante (MEL0; ROMANINI, 2008).

Arborizar é incluir espécies vegetais nos espaços viários com os objetivos de ornamentar o ambiente urbano, regular o ciclo hidrológico do local e beneficiar a população por meio da geração de melhorias na qualidade de vida (BENATTI et al., 2012). Segundo Gonçalves (2000), a definição de arborização urbana tem dado lugar a um conceito mais abrangente e a nova área do saber denominada "silvicultura urbana", por se entender que os agrupamentos de árvores são mais significativos que árvores isoladas.

Nas grades cidades, de modo a amenizar os problemas originados pela urbanização, é necessário incluir a vegetação como um fator indispensável no planejamento urbano (SANTOS et al., 2018). Conforme a CEMIG (2011), a arborização das cidades, além da estratégia de amenização de aspectos ambientais adversos, é importante sob os aspectos ecológico, histórico, cultural, social, estético e paisagístico, contribuindo para: a manutenção microclimática, conforto térmico associado à umidade do ar e à sombra, melhoria da qualidade do ar, redução da poluição, melhoria da infiltração da água no solo, o embelezamento da cidade, proporcionando prazer estético e bem-estar psicológico. 
Entretanto, a maioria das cidades cresceu de forma desordenada, sem nenhum planejamento urbanístico. Portanto, torna-se necessário o planejamento da arborização urbana nas cidades com base não só em seus valores estéticos, mas nos serviços ecossistêmicos que ela desempenha para a melhoria da qualidade de vida (DUARTE et al., 2018). Um plantio mal planejado causa vários problemas: como o conflito arbóreo com redes elétricas, impedimento de visualização de sinais e placas, conflito com os postes de iluminação, rachaduras em calçadas causada pela exposição de raízes, entupimento de bueiros e calhas, obstáculos para a circulação de veículos nas vias e dificuldade para a passagem de pedestres (SILVA et al., 2018). A arborização não planejada gera prejuízos para o ambiente.

0 manejo arbóreo no espaço urbano visa atender e eliminar tais conflitos, de modo a interferir o mínimo possível no vegetal e evitar danos ao ambiente.

Assim sendo, o planejamento deve ser feito levando em conta a necessidade de compatibilização entre o porte e a forma da árvore com o espaço físico disponível, considerando o afastamento predial, a largura das ruas e calçadas, o tipo de tráfego local, e a adaptação que a espécie arbórea terá de acordo com o clima local (CECCHETT0 et al., 2014).

Nesse contexto, foi realizado um censo arbóreo com objetivo de conhecer o patrimônio arbustivo, a partir do levantamento de dados sobre cada indivíduo presente no local. Para Santos et al (2015), o inventário das árvores é uma ferramenta fundamental para as etapas de manejo, e no caso específico da arborização urbana, busca-se obter informações qualiquantitativas, fornecendo informações precisas de poda, remoção e plantios, ou tratamentos fitossanitários.

Este trabalho teve como objetivo realizar um diagnóstico qualitativo e quantitativo da arborização urbana do bairro do Grajaú, na cidade do Rio de Janeiro e identificar os principais conflitos existentes com os elementos urbanos para orientação das técnicas de manejo.

\section{MATERIAL E MÉTODOS}

\section{Caracterização da área de estudo}

0 estudo foi realizado no bairro do Grajaú, localizado na chamada Grande Tijuca na Zona Norte da cidade do Rio de Janeiro (RJ), região próxima ao Maciço da Tijuca. 0 clima é tropical de acordo com a classificação de Köppen-Geiger, com chuvas no verão e altas temperaturas, sendo no inverno há o predomínio do ar seco e temperaturas amenas. 0 bairro Grajaú caracteriza-se em sua maioria como residencial. 
Diagnóstico e análise dos conflitos da arborização urbana: estudo de caso do bairro do Grajaú (Rio de Janeiro)

\section{Coleta de dados}

0 censo arbóreo quali-quantitativo foi realizado no período de agosto a novembro de 2016, na qual todas as árvores do bairro foram cadastras. A escolha do bairro em detrimento aos demais foi baseada na alta demanda pela poda de árvores solicitadas pela população.

Os dados foram coletados pela Companhia Municipal de Limpeza Urbana - COMLURB. Utilizou-se como ferramenta para a preenchimento do censo arbóreo o Sistema de Informação Geográfica (SIG) e os dados foram coletados online através do aplicativo Collector for ArcGis, o que permitiu uma contínua atualização das informações.

Para o preenchimento do banco de dados, foram determinados os seguintes parâmetros, avaliando-se:

a) Tipo de via, logradouro, número da casa, bairro, fluxo da via, sentido da via e a situação do estacionamento no local. Tais informações são necessárias para a localização do vegetal.

b) Nome vulgar da espécie: nome popular.

c) Rede área: classificada em rede doméstica (RD), baixa tensão (BT), média tensão (MT) e não existente (NE). Esse campo tem como finalidade informar o tipo de rede elétrica sobre a copa do vegetal.

d) Dendrometria do vegetal: altura, diâmetro na altura do peito (DAP) e diâmetro de copa médio (DC_MEDI0).

e) Equilíbrio da copa: foi avaliado como copa ausente, copa equilibrada, copa medianamente equilibrada (maior quantidade de copa de um lado da árvore) e não equilibrada. De acordo com a situação da copa, o vegetal pode apresentar risco de queda.

f) Danos à raiz: avaliaram-se as condições em que as raízes se encontram. Classificouse o sistema radicular como, não foi possível constatar danos, gola cimentada, danos leves, danos moderados e danos graves.

g) Conflito com pedestre: árvores de até 3 metros podem dificultar a passagem de pedestres nas calçadas.

h) Conflito com via de trânsito: dependendo do crescimento da árvore, a copa pode obstruir a via de trânsito.

i) Conflito com sinalização: em alguns casos foi possível verificar que a copa das árvores impedia a visibilidade de placas de sinalização. 
j) Conflito com poste de iluminação: condições em que a copa dos vegetais encontra-se muito próxima a postes de luz, ou devido ao diâmetro da copa interferir no cone de iluminação.

k) Conflito com fachada e telhado: avaliaram-se que as árvores apresentavam conflitos com as edificações e telhados das casas.

l) Conflito com rede elétrica: Interceptação dos vegetais com as fiações elétricas.

Utilizou-se o software Microsoft Excel, com auxílio das ferramentas de tabela dinâmica, filtro, gráficos e tabelas, para tabulação dos dados.

\section{RESULTADOS E DISCUSSÃ0}

\section{Caracterização florística e diversidade de espécies}

Foram identificadas e georreferenciados 2.733 indivíduos arbóreos, pertencentes a 56 espécies, distribuídos em 22 ruas e avenidas no bairro do Grajaú. A Avenida Júlio Furtado, seguida da Rua Itabaiana, foram as vias com maior número de plantas arbustivas.

A Tabela 1 apresenta as quinze espécies de maior ocorrência na área de estudo, representando 78\% dos indivíduos inventariados. A Amendoeira (Terminalia Catappa L.) é a espécie de maior abundância, com 423 indivíduos, responsável por uma frequência de 15\% em relação ao total de árvores. Em segundo o Oiti (Licania Tomentosa (Benth.) Fritsch) com 290 indivíduos (11\%) e a terceira mais abundante o Flamboynt (Delonix regia) com 256 indivíduos $(9 \%)$.

Tabela 1. Quinze espécies de maior ocorrência no bairro do Grajaú, cidade do Rio de Janeiro, RJ.

\begin{tabular}{lllll}
\hline Nome Vulgar & Nome Científico & $\mathrm{N}^{\mathbf{0}}$.ind & F(\%) & FA(\%) \\
\hline Amendoeira & Terminalia Catappa L. & 423 & $15 \%$ & $15 \%$ \\
Oiti & Licania Tomentosa(Benth.) Fritsch & 290 & $11 \%$ & $26 \%$ \\
Flamboyant & Delonix regia (Hook.) Raf. & 256 & $9 \%$ & $35 \%$ \\
Tamarindeiro & Tamarindus indica L. & 244 & $9 \%$ & $44 \%$ \\
Ipê & Handroanthus SP. & 163 & $6 \%$ & $50 \%$ \\
Senna Sianea & Senna Siamea (Lan) H.S. Irwin \& Barneby & 156 & $6 \%$ & $56 \%$ \\
Munguba & Pachira aquatica Aubl. & 155 & $6 \%$ & $62 \%$ \\
Ficus & Ficus sp. & 123 & $5 \%$ & $66 \%$ \\
Sibipiruna & Caesalpinia pluviosa (DC.) L. P. Queiros & 82 & $3 \%$ & $69 \%$ \\
Jasmim manga & Plumeria rubra L. & 65 & $2 \%$ & $72 \%$ \\
Pata-de-vaca & Bauhinia variegata L. & 53 & $2 \%$ & $74 \%$ \\
Pau- brasil & Caesalpinia echinata & 44 & $2 \%$ & $75 \%$
\end{tabular}


Diagnóstico e análise dos conflitos da arborização urbana: estudo de caso do bairro do Grajaú (Rio de Janeiro)

\begin{tabular}{lllll} 
Palmeira & Arecaceae & 36 & $1 \%$ & $76 \%$ \\
Goiabeira & Psidium guajava L. & 29 & $1 \%$ & $78 \%$ \\
Albizia & Albizia lebbeck (L.) Benth. & 13 & $0 \%$ & $78 \%$ \\
\hline Total & & 2132 & $78 \%$ & - \\
\hline
\end{tabular}

Nota: $\mathrm{N}^{\circ}$.ind = número de indivíduos; $\mathrm{F}(\%)$ = frequência; $\mathrm{FA}(\%)$ = frequência acumulada.

Fonte: 0 autor.

0 número de espécies encontradas no bairro do Grajaú-RJ pode ser considerado baixo, quando comparado a outros levantamentos realizados em locais de semelhante extensão: 58 espécies de 3301 indivíduos -Mamborê/PR (DAMACEN0 et al, 2017), mais de 100 espécies de 3654 indivíduos analisados - São Pedro/SP (SILVA FILHO; B0RTOLET0, 2005) e 868 indivíduos catalogados em 71 espécies arbóreas - Salto de Pirapora/SP (BENATTI et al., 2012). Segundo Melo e Lira (2007), a predominância de apenas uma espécie ou grupo de espécies pode facilitar em alguns casos, a propagação das pragas, atualmente muito comum nas árvores urbanas.

Nesse sentido, é possível verificar que as três espécies de maior ocorrência, juntas totalizam uma frequência acumulada de $35 \%$ do total de espécies no bairro. Na arborização urbana é comum que diversidade das espécies seja baixa, onde a maior parte das árvores é representada por poucas espécies.

Entre as quinze espécies de maior ocorrência no bairro, Amendoeira, Flamboyant, Senna Siamea, Munguba e Ficus, segundo o Plano Diretor de Arborização Urbana do Rio de Janeiro - PDAU (2015) são listadas entre as dez piores para a arborização urbana. Há uma relação direta entre fortes chuvas e rajadas de vento e queda de árvores. Outros fatores que contribuem para a falência do vegetal são as características da espécie, sistema radicular e sanidade da árvore (PDAU, 2015).

A Amendoeira (Terminalia Catappa L.) não é uma espécie indicada pra arborização urbana, pois é uma espécie que apresenta conflitos com fachadas e telhados, devido à grande extensão de sua copa e conflito com redes aéreas. Segundo Rocha et al.(2004), a Amendoeira é uma espécie que possui folhas grandes, que se desprendem das árvores, sujando as calçadas e ruas, e causam entupimento da rede pluvial. 0 Flamboyant (Delonix regia (Hook.) Raf.), terceira espécie de maior ocorrência, encontra-se entre as mais frequentes em incidência de queda, por apresentar raízes superficiais.

Seguido da Amendoeira, o Oiti (Licania Tomentosa (Benth.) Fritsch) foi a segunda espécie de maior ocorrência no bairro, com 11\%. De acordo com o PDAU (2015), o 0iti é uma espécie nativa da Mata Atlântica, com presença marcante na arborização da cidade do Rio de Janeiro, devido à introdução através de projetos no período colonial e aparece no próprio 
documento entre as dez espécies consideradas como as mais adequadas para a arborização urbana, não apresentando restrições a seus usos. A espécie possui folhas perenes, sistema radicular profundo que não afeta o calçamento e copa densa que propicia sombreamento nas ruas (LORENZI, 1998). Em estudo realizado por Moura et al.(2013), em Itaúna do Sul-PR, comprova o Oiti como sendo uma espécie adequada para arborização urbana, nos dados referentes ao afloramento das raízes, os 0itis foram a espécie que menos apresentou conflitos com 14,63\%, pois se tratam de árvores com sistema radicular apropriado. A implantação do Oiti reflete resultados positivos, onde além dele, contam também a Sibipiruna, Pau-Brasil, Ipê e Jasmim-Manga, consideradas adequadas para a arborização em espaços urbanos.

Em relação às espécies frutíferas, destacam-se a Munguba (Pachira aquatica Aubl.) e a Goiabeira (PSidium guajava L.) o uso dessas espécies no espaço urbano, causam resíduos orgânicos nas vias públicas, servem de alimentos para vetores e dependendo do tamanho do fruto podem causar danos e acidentes. Apesar da Munguba ser uma espécie amplamente difundida pelo bairro e proporcionar um bom sombreamento, seu fruto é grande e pesado, podendo causar prejuízos.

\section{Situação do sistema radicular}

Quanto ao sistema radicular das árvores, avaliou-se os possíveis danos à raiz, que foram parametrizados em cinco categorias: (I) não foi possível constatar danos, (II) gola cimentada quando se observa cimento até a base do vegetal, (III) danos leves quando se observa cortes leves na raiz, (IV) danos moderados quando se observa corte nas raízes de sustentação e (V) danos graves quando se observa cortes verticais em raízes de sustentação próximos a base ou cortes horizontais com perda significativa do tecido vegetal.

As árvores plantadas em espaços urbanos via de regra sofrem interferências antrópicas, e estão sujeitas a pisoteio, com possibilidade de compactação, acumulo de lixo, sofrem interferência da construção civil, e ainda como no caso da Avenida Júlio furtado, principal avenida do Grajaú, os carros estacionam sobre as raízes das árvores.

Analisando os dados no Gráfico 1, observa-se que os indivíduos com danos leves representam 9,1\%, gola cimentada $2,5 \%$, danos moderados $1,2 \%$ e danos graves $0,6 \%$ do total de árvores vistoriadas. 0s resultados refletem um parecer favorável, onde em geral o bairro demonstrou um bom estado de fitossanidade das raízes expostas, com poucas árvores apresentando danos graves. Do total das árvores do bairro apenas 13,4\% apontam algum tipo de dano. 
Diagnóstico e análise dos conflitos da arborização urbana: estudo de caso do bairro do Grajaú (Rio de Janeiro)

Gráfico 1. Situação das raízes das árvores.

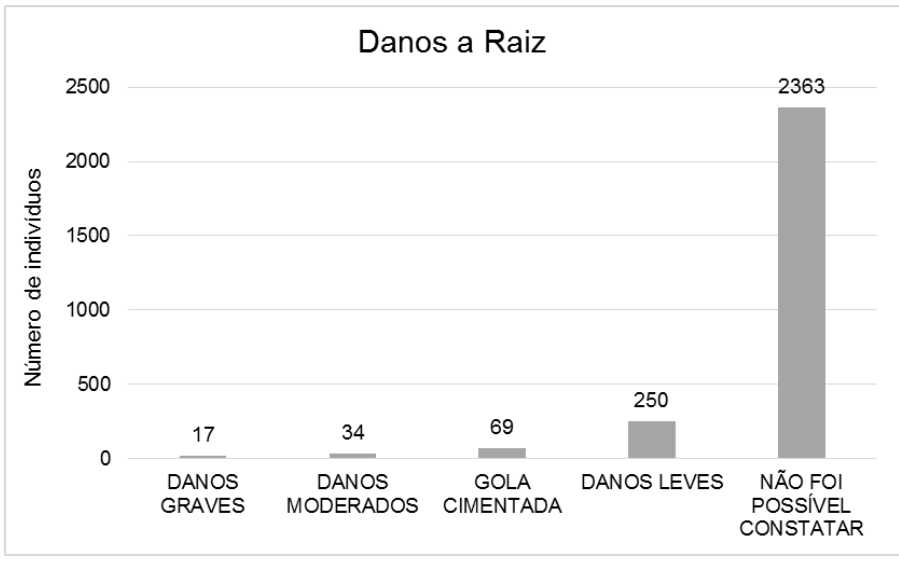

Fonte: 0 autor.

Em relação ao caso das árvores com danos graves à raiz, dos 17 indivíduos constatados com danos graves, 13 encontram-se localizados na Avenida Júlio Furtado, no Grajaú. Os tamarindeiros localizados no canteiro central da Avenida formam um verdadeiro corredor verde pelo bairro e sofrem drasticamente interferências antrópicas. As árvores não possuem cinta de proteção e nem a área de crescimento delimitada. Em estudo semelhante desenvolvido por Benatti et al. (2012), constatou-se no inventário arbóreo do município de Salto de Pirapora-SP, um percentual aproximado de 70\% das árvores não interferirem de forma direta na calçada. Desse modo, pode-se dizer que há grande fração dos indivíduos arbóreos no meio urbano que não geram conflito com passeio público.

\section{Situação das copas das árvores}

A grande maioria dos indivíduos arbóreos apresentam um parecer favorável em relação à copa das árvores. Constata-se uma porcentagem pequena de indivíduos que possuem a copa desequilibrada (3,2\%), equivalente a 87 indivíduos. As espécies mais problemáticas em relação a copa desequilibrada são Amendoeira e Flamboyant, com 20 indivíduos cada espécie. Em relação à copa ausente, foram detectadas 36 árvores. Esse problema pode ser decorrente de poda mal realizada ou algum problema de fitossanidade da árvore. De acordo com a situação da copa, o vegetal pode apresentar iminente risco de queda, por causa do desequilíbrio causado.

A Figura 1 apresenta a localização espacial dos 87 indivíduos diagnosticados com copa desequilibrada. As análises desses dados permitem antecipar o manejo arbóreo de forma 
inteligente, priorizando os casos de maior risco no bairro, em detrimento aos demais, detectando as prioridades, a fim de evitar prejuízos ambientais, sociais e econômicos.

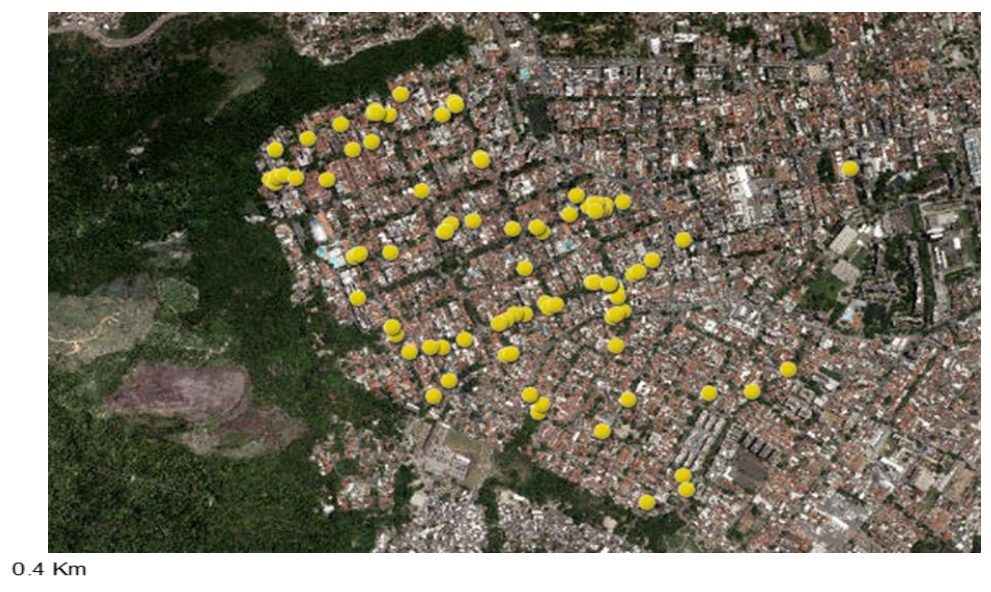

Escala:

Figura 1. Localização das árvores com copa desequilibrada.

Fonte: Aplicativo Collector for ArcGis.

\section{Conflitos urbanos}

No meio urbano, as árvores então sujeitas às condições impróprias, devidos a elementos viários presentes como: poste de iluminação pública, elementos de sinalização de trânsito, telhados, edificações, conflito com via, circulação de pedestre e com a rede elétrica.

0 Gráfico 2 exemplifica os sete conflitos levantados no bairro. 0s principais problemas registrados no levantamento de campo evidenciam um maior conflito com fachada, via, telhado e rede. Os problemas relacionados com pedestre, sinalização e iluminação não foram muito expressivos, representando uma baixa ocorrência.

Gráfico 2. Conflitos urbanos.

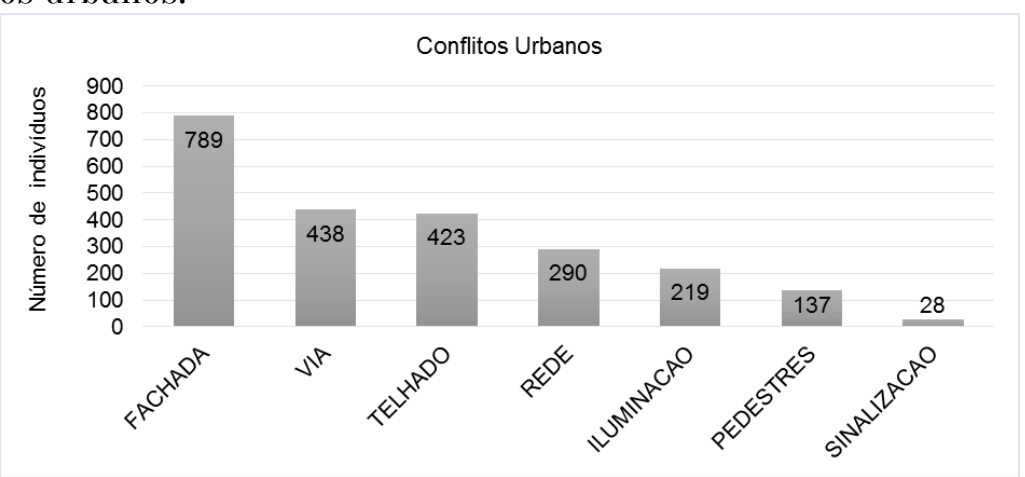

Fonte: 0 autor. 
Diagnóstico e análise dos conflitos da arborização urbana: estudo de caso do bairro do Grajaú (Rio de Janeiro)

0 principal conflito existente é com a fachada, onde foram detectados 789 indivíduos. Quando distribuídos em classes de altura, sua maior representação se concentra nas árvores com mais de 9,0 m de altura. Em segunda posição, com maior número de ocorrência é conflito com a via, 438 árvores. Conflito com o telhado ocupa o terceiro lugar de maior ocorrência, com 423 indivíduos. 0 bairro do Grajaú, é, em sua maioria, residencial, composto por casas e prédios de até 6 pavimentos, o que explica 0 grande número de interferências por fachadas e telhados.

Em muitas ocasiões o espaço disponível de calçada para o desenvolvimento de uma espécie arbórea é insuficiente, a copa do exemplar arbóreo acaba em conflito com janelas, telhados ou outras estruturas do imóvel, tal conflito pode ocasionar danos ao imóvel como quebra de telhas, janelas e outros danos físicos. 0 bairro possui árvores antigas e de grande porte, não houve um planejamento prévio no desenvolvimento da urbanização do bairro, que acompanhasse o crescimento da arborização, a fim de evitar problemas futuros.

De forma comparativa ao estudo realizado por Silva et al. (2016), no bairro Centro da Cidade do Rio de Janeiro, o principal conflito encontrado foi com fachada, observaram-se 785 indivíduos, no total de 3874 árvores. Contudo, a maior parte dos lagradouros do Centro do Rio de Janeiro são prédios, o que se explica também a faixa da classe de altura em que mais há conflito, são árvores com mais de 9,4 m de altura.

Quanto ao conflito com via, no Grajaú, 438 indivíduos foram registrados com essa ocorrência. Árvores com altura superior a 9,0 m representam a maioria nessa situação. Em alguns casos o fuste dos indivíduos disputam espaço na rua com os ônibus e o atrito pode vir a causar lesão no fuste e comprometer a fitossanidade da planta, ou ainda, a copa da árvore está projetada para via e obstrui a visibilidade dos motoristas, causando interferência com os veículos.

No que tange ao conflito com rede elétrica, observou-se 290 árvores com incompatibilidade com a fiação elétrica. De maneira semelhante, na pesquisa de Batista et al. (2018) realizada em Belém-PA, do total amostrado 54,62\% dos indivíduos apresentavam conflito com a rede aérea, segundo os autores esse fato está relacionado às práticas inadequadas de podas. Dentre os elementos urbanos conflitante com as árvores, a realização da poda para livrar da rede aérea a copa das árvores é um dos mais complexo, devido ao risco iminente da atividade (Tabela 2). 
Tabela 2 - Número de indivíduos separados em quatro classes de altura relacionados com os 4 conflitos de mais ocorrência no bairro do Grajaú.

\begin{tabular}{lllll}
\hline Classe de Altura $(\mathrm{m})$ & Fachada & Via & Telhado & Rede \\
\hline $\mathrm{H} \leq 5,0$ & 8 & 28 & 0 & 24 \\
$5,0<\mathrm{H} \leq 7,0$ & 50 & 68 & 5 & 51 \\
$7,0<\mathrm{H} \leq 9,0$ & 92 & 75 & 23 & 55 \\
$\mathrm{H}>9,0$ & 639 & 267 & 395 & 160 \\
\cline { 2 - 5 } Total Geral & 789 & 438 & 423 & 290 \\
\hline
\end{tabular}

Os indivíduos arbóreos com altura entre 7,0 e 9,0 m, apresentam conflito com as redes domésticas e de baixa tensão. 0 maior número de conflitos e mais expressivo ocorre nas árvores com mais de 9,0 m de altura, representando 160 indivíduos. Nos locais com rede de média tensão, é necessário o desligamento da rede de energia, para a execução do manejo com segurança. As árvores com menos 5,0 m de altura, expressam 1\%, do total de árvores conflitantes com a rede.

Valesco et al. (2006) propõe alternativas quanto ao uso da rede convencional de energia, como por exemplo, o uso de rede compactada ou rede subterrânea. 0 custo para a implementação da rede compactada é praticamente o mesmo da rede convencional e há uma redução de $80 \%$ no custo com manutenção. É vantajoso financeiramente e permite uma melhor convivência com as árvores sobre o espaço urbano.

\section{CONCLUSÃO}

Com base no censo arbóreo realizado no bairro do Grajaú, os resultados apontam 2733 indivíduos arbóreos, pertencentes a 56 espécies levantadas, com predominância da Amendoeira (Terminalia Catappa L.), seguida por Oiti (Licania Tomentosa (Benth.) Fritsch) em relação ao total de árvores. A maior Avenida do bairro e a mais arborizada, Avenida Júlio Furtado, apresenta o maior índice de árvores com danos graves na raiz, contudo os indivíduos com injúrias representam $0,62 \%$ do total inventariado.

Foram detectados 87 indivíduos com copa desequilibrada, o que representa 3,2\% do total inventariado no bairro. Os conflitos urbanos mais expressivos são: fachada, via, telhado e rede elétrica. A grande demanda por manejo arbóreo ocorre em função do grande número de 
Diagnóstico e análise dos conflitos da arborização urbana: estudo de caso do bairro do Grajaú (Rio de Janeiro)

árvores no bairro e a maioria de grande porte, com mais de 9,0 m de altura e interferem em algum elemento urbano.

No meio urbano faz-se necessário um planejamento estratégico e uma gestão contínua para a arborização de ruas e avenidas. Espera-se que a utilização da tecnologia SIG como ferramenta para o manejo arbóreo possa fornecer subsídios para melhor gestão da arborização urbana. A partir do levantamento de dados sobre cada indivíduo presente no local, é possível uma melhor gestão, priorizando os casos mais graves em detrimento aos demais.

Após diagnóstico, sugere-se remoção das árvores em declínio, combate a pragas, doenças e a realização de podas preventivas no bairro com o propósito de conduzir 0 crescimento das árvores para evitar prejuízo futuros. Nos logradouros onde as calçadas são estreitas ou existe rede elétrica, deve-se limitar a espécies de pequeno porte. 0 êxito na silvicultura urbana irá depender da escolha adequada da espécie e as possíveis proteções para o sistema radicular. É um processo delicado que exige cuidados desde a concepção até a implantação e manutenção.

\section{AGRADECIMENTOS}

A Companhia Municipal de Limpeza Urbana (COMLURB) do Estado do Rio de Janeiro, pelas informações cedidas. Agradeço também à Universidade Federal Fluminense e a todos os professores que acompanharam minha jornada enquanto universitária e que foram essenciais a minha formação como profissional.

\section{REFERÊNCIAS BIBLIOGRÁFICAS}

BATISTA, D.B.; BATISTA, A.C.; SILVA, D.A. Avaliação qualitativa da arborização com Mangifera indica nas ruas de Belém-PA. Acta Biológica Catarinense, v. 5, n. 1, p. 34-45, 2018.

BENATTI, D. P.; TONELlO, K. C., ADRIANO JÚNIOR, F. C., SILVA, J. M. A. S.; OLIVEIRA, I. R.; ROLIM, E. N.; FERRAZ D. L. Inventário arbóreo-urbano do município de salto de Pirapora, sp. Revista Árvore, Viçosa, v.36, n.5, p.887- 894, 2012.

CECCHETTO, C. T.; S. S.CHRISTMANN; T. D. OLIVEIRA. Arborização urbana: importância e benefício no planejamento ambiental das cidades. Anais. XVI Seminário Internacional de Educação no Mercosul. Cruz Alta, RS, p. 1-13, 2014.

CEMIG. Energética de Minas Gerais. Manual de arborização. Belo Horizonte: Cemig / Fundação Biodiversitas, p.l12, 2011. Disponível em: $\quad$ http://www.cemig.com.br/ptbr/atendimento/Documents/Manual_Arborizacao_Cemig_Biodiversitas.pdf > Acesso em: 25/09/2018.

DUARTE, T. E. P. N., ANGEOLETTO, F., SANTOS, J. W. M. C., SILVA, F. F., BOHRER, J. F. C., MASSAD, L. REFLEXÕES SOBRE ARBORIZAÇÃO URBANA: DESAFIOS A SEREM SUPERADOS PARA 0 INCREMENTO DA ARBORIZAÇÃO URBANA NO BRASIL. Revista em Agronegócio e Meio Ambiente, v. 11, n. 1, p. 327-341, 2018. 
G0NÇALVES, W. Florestas urbanas. Ação ambiental, Ano II, n.9, p.17-19, 2000.

DAMACENO, F. M.; NETO, S. P.; CARARD, R. F.; DA CUNHA, C. C.; DOS REIS, R. A.; CAXAMBU, M. G. Censo da Arborização urbana do Município de Mamborê, Paraná. SaBios-Revista de Saúde e Biologia, v. 12, n. 2, p. 10-19, 2017.

LORENZI, H. Árvores brasileiras: manual de identificação e cultivo de plantas arbóreas nativas do Brasil. 2. ed. Nova Odessa, Plantarum, v.2, p.352,1998.

MELO, E.F.R.Q.; ROMANINI, A. Praça Ernesto Tochetto: importância da sua preservação histórica e aspectos de sua arborização. Revista da Sociedade Brasileira de Arborização Urbana, Piracicaba, v.3, n.1, p.54-72, mar, 2008.

MELO, R. R.; LIRA FILHO, J. A.; RODOLFO JÚNIOR, F. Diagnóstico qualitativo e quantitativo da arborização urbana no bairro Bivar Olinto, Patos, Paraíba. Revista da Sociedade Brasileira de Arborização Urbana, Piracicaba, v.2, n.1, p.6478, 2007.

MOURA, T, A.; GIMENES, G, C, S.; PIRES, M, M, Y. Levantamento da arborização das avenidas Brasil e São Paulo do município de Itaúna do sul-pr. Revista Terra \& Cultura: Cadernos de Ensino e Pesquisa, v. 29, n. 57, p. 59-68, 2013.

PDAU. Plano diretor de arborização urbana da cidade do Rio de Janeiro. Rio de Janeiro: FPJ, 416.p,2015. Disponível em: $<$ http://www.rio.rj.gov.br/dlstatic/10112/5560381/4146113/PDAUtotal5.pdf $>$ Acesso em: 25/09/2018.

ROCHA, R. T.; LELES, P. S. S.; OLIVEIRA NETO, S. N. Arborização de vias públicas em Nova Iguaçu, RJ: o caso dos bairros Rancho Novo e Centro. Revista Árvore, Viçosa, v.28, n.4, p.599-607, 2004.

SANTOS, C. Z. A.; FERREIRA, R. A.; SANTOS, L. R.; SANTOS, L. I.; GOMES, S. H., GRAÇ, D. A. S. Análise qualitativa da arborização urbana de 25 vias públicas da cidade de Aracaju - SE. Ciência Florestal, v. 25, n. 3, p. 751-763, 2015.

SANTOS, M. 0.; MAIA, L. P. S. S.; OLIVEIRA, E. D.; SILVA NETO, J. C. A.; CELLA, W. Percepção Ambiental sobre a Arborização Urbana no Bairro Santa Tereza, Tefé, Amazonas, Brasil. Revista Raoega, Curitiba, v. 44, p. 231-241, mai., 2018.

SILVA FILHO, D, F; BORTOLETO, S. Uso de indicadores de diversidade na definição de plano de manejo de arborização viária de águas de São Pedro - SP. Revista Árvore, Viçosa, v. 29, n. 6, p. 973-981, Dec, 2005.

SILVA, L. A. C., LINS, D. A. W., CARVALHO, A. de.; ROCHA, A. P. Análise quali-quantitativa da composição arbórea do bairro da Encruzilhada. Revista Brasileira de Meio Ambiente, Recife, v. 4, n. 1, 2018.

SILVA, K.R.; LELES, P.S.S.; GIÁCOM0, R.G.; MENDONÇA, B.A.F. Diagnóstico e uso de geoprocessamento para o manejo da arborização urbana do bairro Centro da Cidade do Rio de Janeiro-RJ. Revista da Sociedade Brasileira de Arborização Urbana, Piracicaba, v.11, n.4, p.98-114, 2016.

VELASCO, G. D. N.; LIMA, A. M. L. P.; COUTO, H. T. Z. Análise comparativa dos custos de diferentes redes de distribuição de energia elétrica no contexto da arborização urbana. Revista Árvore, Viçosa, v.30, n.4, p.679-686, 2006. 